\title{
Impacts of Distributed Generation on Low-Voltage Distribution Network Protection
}

\author{
Richard Ogden, Jin Yang \\ School of Engineering and Applied Science, Aston University, Birmingham, B4 7ET, U.K. \\ E-mail: ogdenr@aston.ac.uk,j.yang8@aston.ac.uk
}

\begin{abstract}
This paper reports work of a MEng student final year project, which looks in detail at the impacts that distributed generation can have on existing low-voltage distribution network protection systems. After a review of up-to-date protection issues, this paper will investigate several key issues that face distributed generation connections when it comes to network protection systems. These issues include, the blinding of protection systems, failure to automatically reclose, unintentional islanding, loss of mains power and the false tripping of feeders. Each of these problems impacts on protection systems in its own way. This study aims to review and investigate these problems via simulation demonstrations on one representative network to recommend solutions to practices.
\end{abstract}

Index Terms - Low-voltage Distribution Network, Distributed Generation, Protection Systems

\section{INTRODUCTION}

To facilitate low carbon operation of the low-voltage distribution networks (LVDN), a growing number of powerelectronic converters (PECs) are used to interface small/medium scale distributed energy resources (DERs) for renewable distributed generation (DG) and smart electricity end-use devices, such as wind turbines, photovoltaic (PV) panels, energy storages, electric vehicles, intelligently controlled appliances. In addition, the system should be allowed to operate as separate islands (Microgrids) to reduce customer interruption (CI), customer minute loss (CML), and implement autonomously controlled strategies. The fact that power flows are bi-directional results in a name of "active distribution network." Advantages of active distribution networks are seen as incorporating renewable generations, reducing transmission network losses and usage to prevent network congestions; islanded microgrid operation in case of upstream system disturbances. However, disadvantages are also seen, one of the major crucial challenges is that the existing protection system needs to be adapted.

\section{LOW-VOLTAGE DiSTRIBUTION NETWORK PROTECTION AND DISTRIBUTED GENERATION}

The conventional LVDN protection system is designed for overcurrent operations. All protective devices (from secondary substation, e.g. $11 \mathrm{kV} / 0.4 \mathrm{kV}$ circuit breakers to dominant fuses in $0.4 \mathrm{kV} \mathrm{LV}$ branches and end-users) are coordinated for grid-connected mode of operations, i.e. the fault current is expected to be sufficiently large to force the fuses to act. This is still required during islanded operation, when high fault-currents are only provided from DGs, which can be converter interfaced with limited fault-current feeding capabilities. As more DGs are being used with or without PEC the current protection system needs to be reconsidered to act in an island mode or a grid mode. In the island mode the DG can operate by itself and can feed into the consumer supply assuming the renewable resource (e.g. solar radiation or wind) is available to help generate the electricity. In grid mode the DG can connect to the grid and is able to feed into the grid. Due to these two separate modes, a revised protection system needs to be designed as the fault levels for islanding mode and grid mode are different.

\section{PROTECTION Challenges FROM Distributed GENERATION CONNECTIONS - PREVIOUS AND CURRENT RESEARCH}

Due to inadequate fault currents the coordination may be compromised in the islanded mode of operation. Such i.e., small fault currents can result in a slow operation of network overcurrent devices, unless these devices are made more sensitive. However this will have an effect on coordination particularly. Therefore, conventional relay and fuse coordination and generic overcurrent protection with a single setting group may become inadequate. Previous and current researches report on the following aspects:

A. Fault Level Analysis

Network topology can have an effect on the fault level. It also appears that the type of DG and the load ratings can cause differing fault levels [1]-[3]. For example paper [1] provides an in-depth look at the fault analysis for a sizeable grid involving 4 DGs rated at 5MW each and 27 buses. This paper gives a good example of how much detail in terms of carrying out fault level analysis.

\section{B. Blinding of Protection Systems/False Tripping of Feeders}

As stated above when a DG is connected to a network it can change the fault current value that is seen by the protection overcurrent relay. This can prevent the reliable tripping of the overcurrent relay in fault conditions. The false tripping of feeders is another problem due to the overcurrent that is fed by the DG, which is typically caused by synchronous generators [4]. In [5] it is suggested that the issue of false tripping could be eliminated if a converter based DG were to be used in order to limit its fault current. In [6] where it suggests the use of an inverter that communicates with the overcurrent protection would solve this issue. 


\section{Failure to Automatically Reclose}

Auto reclosing is used to clear any temporary faults on the system. This only takes roughly $100-200 \mathrm{~ms}$, which is normally an effective way of clearing the fault. This method of clearing faults can fail when used with a DG in the system. If the DG's protection system does not trigger during that $100-200 \mathrm{~ms}$ time the auto-recloser takes it means the temporary fault is not cleared from the system and becomes more permanent. Some papers have suggested changing the auto-reclose time to account for the time it would take for the DG protection to trigger [7].

\section{Unintentional Islanding/Loss of Mains Power}

The issue of islanding a section of network with DG has been discussed extensively. In [8], several different case studies with different conditions are used to analyse islanding, especially the unintentional islanding scenario. It shows there is a $10 \%$ change at the PCC and explains that the best way to deal with the unintentional islanding is to use PEC-DER. If the unhealthy part of the network is connected to some form of DG it is able to still operate [9]. In [6] it suggests that there are several designs that could be used to solve the problem of islanding and loss of mains. These methods are, differential protection schemes [10], a balanced combination of different types of DG units for grid connection, having different types of inverter working together [11]. Each of these techniques seems to have potential however only for a particular case.

\section{REPRESENTATIVE NETWORK DEFINITION, PSCAD/EMTDC SIMULATIONS AND DISCUSSIONS}

To provide a pathway of studying protection under the above scenario more systematically, we employed a representative network for simulation and fault analysis as in Fig. 1. To incorporate current distribution network infrastructure development issues, the network topology considered is one feeder in radial configuration up to the primary step-up-side of transformer at the common coupling point. The system under investigation includes multiple timevarying distributed generations, e.g. small-scale wind turbines, photovoltaic panels. Simulation models of the DGs including power conversion systems in Fig. 1 are built with fitted parameters to provide typical values for similar applications. Network and protection configuration data is used in a case study example from literature and an industrial project to show both academic and practical perspectives.

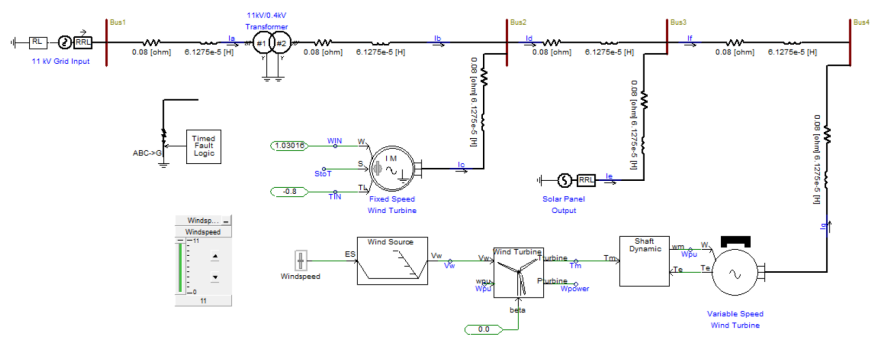

Fig. 1. Schematic of the simulated representative LV distribution network (one feeder).

\section{A. Fault Level Analysis}

Fault level analysis was carried out by applying faults at different locations on the system. Three-phase and singlephase to earth short-circuit fault were applied to each busbar and lasted a duration of 0.5 seconds. The fault current values shown in the Table I are the peak fault current values and are the average of three different results. This was done initially to make sure the first reading was not just a bug or a glitch producing a false result. Once collecting the data it was found that the simulation was reliable and that the same result was consistently produced when the test was run these results were checked against hand calculations. This data was important as it was needed to correctly calibrate the protection systems of the network as it gave a good indication of what sort of fault current level was to be expected. For comparison the normal operating current has also been included.

TABLE I

FAULT LEVEL ANALYSIS RESULTS

\begin{tabular}{|c|c|c|c|c|c|c|c|c|c|c|c|c|c|c|}
\hline \multirow{3}{*}{ Fault Location } & \multicolumn{14}{|c|}{ Fault Current Readings (kA) } \\
\hline & \multicolumn{2}{|c|}{ Ia } & \multicolumn{2}{|c|}{$\mathrm{Ib}$} & \multicolumn{2}{|c|}{ Ic } & \multicolumn{2}{|c|}{ Id } & \multicolumn{2}{|c|}{ Ie } & \multicolumn{2}{|c|}{ If } & \multicolumn{2}{|c|}{ Ig } \\
\hline & $3 \mathrm{ph}$ & $1 \mathrm{ph}$ & $3 \mathrm{ph}$ & $1 \mathrm{ph}$ & $3 \mathrm{ph}$ & $1 \mathrm{ph}$ & $3 \mathrm{ph}$ & $1 \mathrm{ph}$ & $3 \mathrm{ph}$ & $1 \mathrm{ph}$ & $3 \mathrm{ph}$ & $1 \mathrm{ph}$ & $3 \mathrm{ph}$ & $1 \mathrm{ph}$ \\
\hline No Fault & \multicolumn{2}{|c|}{0.006} & \multicolumn{2}{|c|}{0.12} & \multicolumn{2}{|c|}{0.075} & \multicolumn{2}{|c|}{0.05} & \multicolumn{2}{|c|}{0.007} & \multicolumn{2}{|c|}{0.058} & \multicolumn{2}{|c|}{0.058} \\
\hline Bus 1 & 0.044 & 0.042 & 1.2 & 1.2 & 1.02 & 1.23 & 0.286 & 0.238 & 0.16 & 0.124 & 0.305 & 0.17 & 0.31 & 0.17 \\
\hline Bus 2 & 0.12 & 0.118 & 3.3 & 3.2 & 1.34 & 1.77 & 0.285 & 0.275 & 0.14 & 0.134 & 0.31 & 0.2 & 0.31 & 0.29 \\
\hline Bus 3 & 0.078 & 0.059 & 2.1 & 1.6 & 0.7 & 0.81 & 2.1 & 2.15 & 0.15 & 0.1485 & 0.27 & 0.255 & 0.285 & 0.345 \\
\hline Bus 4 & 0.055 & 0.0385 & 1.45 & 1.05 & 0.47 & 0.525 & 1.34 & 1.375 & 0.105 & 0.095 & 1.425 & 1.45 & 0.31 & 0.39 \\
\hline
\end{tabular}

These results show that a fault current in one part of the network is able to affect different parts of the network not just the busbar where the fault has been applied. This is in line with the theory and needs to be considered when designing any protection system, not just for a distributed generation system but for any sort of generation system requiring protection. This is because, as previously mentioned when setting the protection systems for a network there would ideally be layers of protection. This means that there should be a backup relay to clear a fault if the primary protection system were to fail and not detect the fault and clear it. In order to calibrate this protection effectively the impacts of a fault in part of the grid and how it affects the rest of the grid needs to be known. If this is not know the backup protection could not be effectively set up and a fault current in one location could potentially trip the protection systems in 
another part of the system which could cause unnecessary loss of power in another part of the network. These readings are dependent on what sort of distributed generation is connected to the network, if a new generator were to be connected to the network then another fault test like this would have to be done as the initial results would not be valid.

\section{B. Coordination of Protection Systems}

Current observations show that the issues could be solved if all protective devices are automated circuit breaker with modern microprocessor relays, also known as intelligent electronic devices (IEDs), based on advanced communication system. This will be the assumption for the coordination of protective devices in this section.

Fig. 2 shows the test set up for the relay coordination tests. When a fault is applied at its current location the protection systems at location A should activate and open, this protection system should provide the quickest reaction time as it is closest to the fault. Once the protection at location A is confirmed to work it will be taken out of the system to simulate that protection failing. If the protection here fails the protection at point $\mathrm{B}$ should activate and should clear the fault. The protection here will take longer to react as it is further away from the fault location. Once this is confirmed to work the protection at points $\mathrm{A}$ and $\mathrm{B}$ will be removed to simulate both sets of protection systems failing. The fault will then be applied and if set up correctly the protection systems at point $\mathrm{C}$ should activate and clear the fault, this response will be slower than that of the protection systems at point $\mathrm{A}$ and $\mathrm{B}$. If the protection systems pass this test then they will have been correctly set up and will be suitable for further testing.

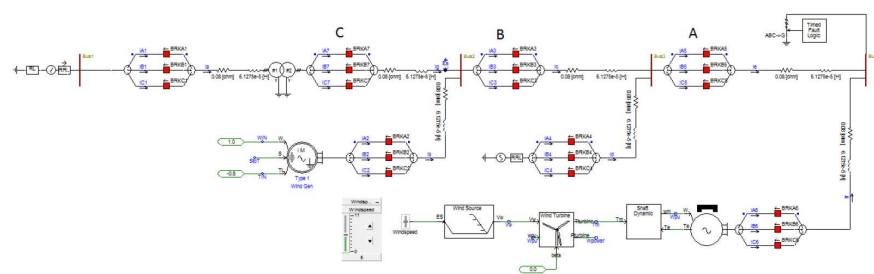

Fig. 2. Relay configuration and coordination test system.

When tested each of the breaker systems at positions A, B and $\mathrm{C}$ were able to detect the fault and activate as shown in Figs. 3-5. This meant they were able to open and clear the fault when the initial protection had failed to operate. The initial fault was applied at 6 seconds into the simulation and had a duration of 0.5 seconds. At location A the fault current is applied at 6 seconds, the protection systems at location A take 0.017 seconds to activate and clear the fault. For this test the protection systems were disabled at location A to see how long it would take for the protection systems at B to activate or if they would activate at all. In this test the protection did active 0.044 seconds after the fault was applied to the network. Here is the test result for the protection system at location C. For this test the other protection systems were disabled to see if the protection systems here would trigger when all other protection systems had failed. The results show that they do activate and take 0.144 seconds to activate.

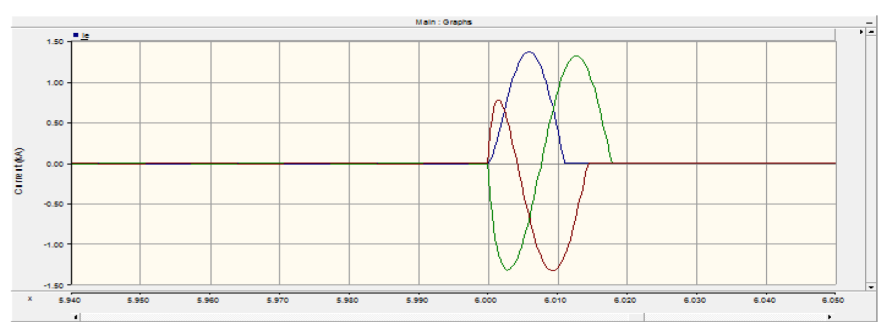

Fig. 3. Fault current at location A.

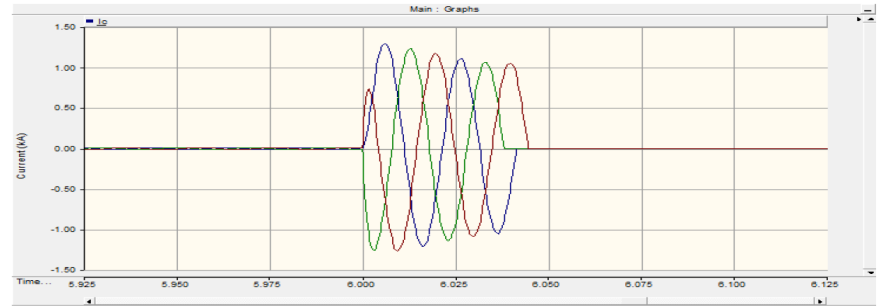

Fig. 4. Fault current at location B.

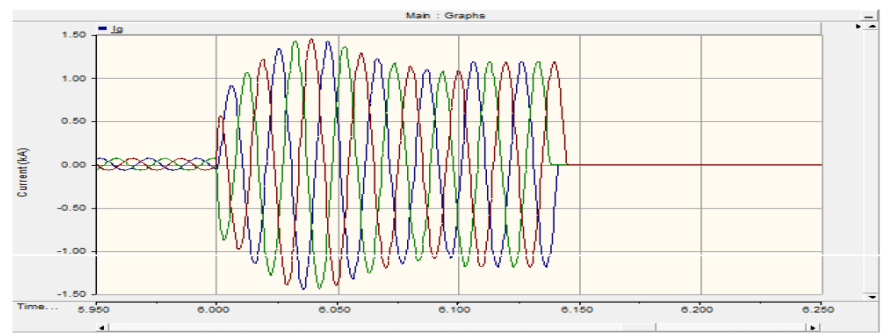

Fig. 5. Fault current at location C.

\section{Failure to Auto-reclose}

As stated in Section II, auto-reclose becomes an issue when the circuit breaker trips and then closes before the fault has been cleared causing an arc. In order to simulate this, a fault was applied for 0.5 seconds. The inverse time relays were then replaced with timed logic blocks so that the circuit breaker opening and closing could take place at a user defined time. Using these timed logic blocks the circuit breaker was to open at 10 seconds when the fault is first detected. The breakers were to then close at 10.3 seconds. This time of operation is in line with typical open and close times of a breaker [7]. As the breaker shut before the fault was over this will give the effect that there was arcing when and the fault shall not be cleared entirely from the network.

Fig. 6 shows the waveform recorded from this experiment. It can be seen that the fault is initially applied at 10 seconds. The circuit breakers impact on the waveform can be seen as they are open until 10.3 seconds. The fault then continues as it has not been cleared as seen by the ripples in the current waveform after 10.5 seconds. 


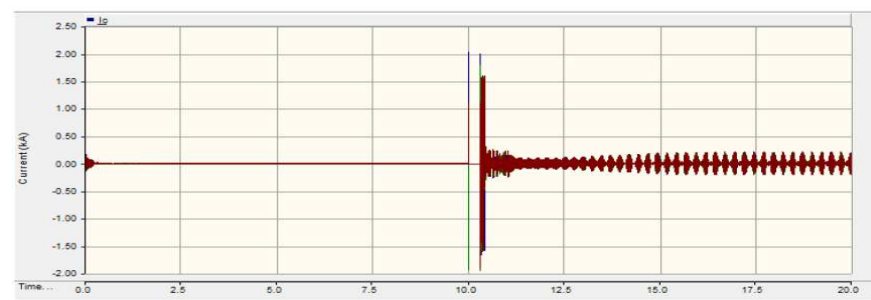

Fig. 6. Simulation results of failure to auto-reclose.

The results for the failure to auto-reclose experiment are in line with the theory stated in the relevant background section in this report. It can be seen in the results that the fault is never cleared from the system and it lasts for the remaining duration of the simulation providing a less than ideal current supply. As this fault current had not been cleared it would have caused damage to other parts of the network due to the high current.

This issue is particularly problematic as the breaker is functioning correctly to try and clear the fault. The issue is with the time that the breaker is open for. There are several solutions to the problem, which are backed by previous research. The first solution would be to increase the reclose time $[12,13]$. There are several issues with this, from a power supply point of view a reclose time of roughly 0.3 seconds has little effect of the quality of the power supplied. A reclose time of much higher, 1 second for example would be able to stop arcing and the fault would be cleared. This increase in time would impact the quality of the power supply seen by the customer so if there were not too many distributed generators connected to a network increasing the reclose time may not have too much of an impact. If there were a higher penetration of distributed generation connected to a network then the 1 second dead time that would be caused by the breaker opening and closing would become much more noticeable. Another potential solution to this problem is to have close synchronisation between the distributed generator and the protection at the fault location. If the protection system at the fault location were able to communicate with the protection systems on the distributed generator then the protection systems at the generator could be triggered. This would stop the distributed generators connected to the system feeding the fault, creating the arc. This solution would not be straight forward to implement in PSCAD as different modules would have to be created to simulate the communications between the different protection systems.

\section{Unintentional Islanding}

In order to simulate unintentional islanding realistically the variable speed wind turbine was to become disconnected from the rest of the network under fault conditions. In this case a fault is applied to bus 4 . This causes the protection systems for bus 4 to activate essentially islanding the variable speed wind turbine while it is still powering a load. In theory once the disconnection has happened the wind turbine should continue to provide power to the load, it will be a lower power than when it was connected to the rest of the system however. After the breaker had tripped and stayed open the voltage and current levels being fed to the load could be monitored, the impact this disconnection had on the rest of the network was also monitored. According to theory along with what was stated in the background section, when the fault occurs the protection should activate and should consequently cut off the variable speed wind turbine from the rest of the system. When this separation happens there should be a decrease in the current provided to the load.

The results in Fig. 7 show that the system has reacted in line with what the theory suggests. The system is providing the required amount of current to the load up until 8 seconds. At 8 seconds a fault is applied which triggers the circuit breakers, disconnecting the wind turbine from the rest of the system shown by the drop in current. Then the wind turbine begins to provide power to the load when not connected to the grid and the load current gradually reduces due to the change in power generation of the wind turbine.

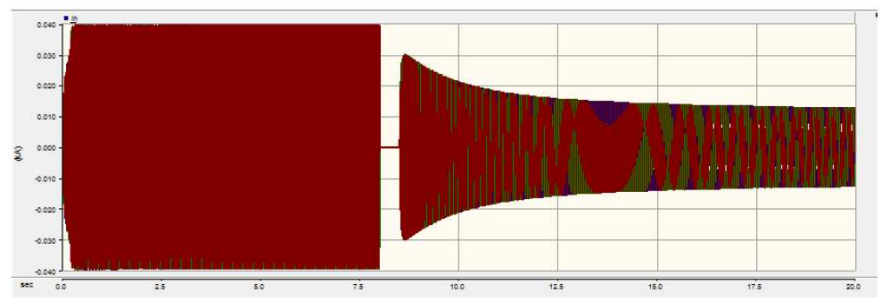

Fig. 7. Simulation results of unintentional islanding.

\section{E. Loss of Mains Power}

This problem was simulated using a three-phase circuit breaker and a timed circuit breaker logic block. To simulate this fault a three phase breaker was placed at the bottom of a feeder that had a the $11 \mathrm{kV}$ grid input on it, using the timed logic block this breaker could be programed to open and stay open at a specific time. This effectively simulated the grid system being cut off from the rest of the network. The impacts of this were then monitored so the changes in the current and voltage levels around the grid system could be analysed. At 6 seconds into the simulation program the timer triggers the breaker to open and stay open. Once the mains have been disconnected a fault was then applied at Bus2 above at 10 seconds into to the simulation. The impact of the loss of mains on the fault protection could then be observed.

When the mains are disconnected from the rest of the network it is expected that there will be a drop in the current provided due to the gird disconnected. When this has happened it is expected to render the current protection systems set up for the grid connection to be ineffective and unable to detect a fault current. The loss of mains test results are shown below in Figs. 8-10.

Fig. 8 shows an overview of the loss of mains test that was carried out. The grid supply was disconnected from the system at 6 seconds. There was then a three-phase fault applied to the system at 10 seconds. Figs. 9 and 10 show the key parts of the wave form in Fig. 8 in more detail. This change in current meant that the circuit breaker in place to 
detect a fault here was not triggered so the fault remained in the network.

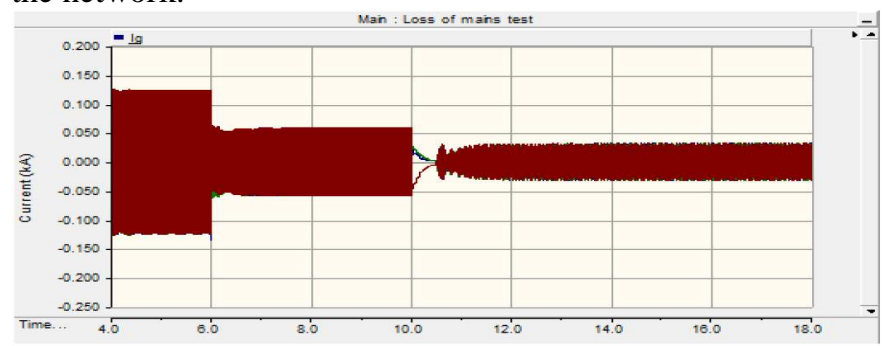

Fig. 8. Overview of the loss of mains results.

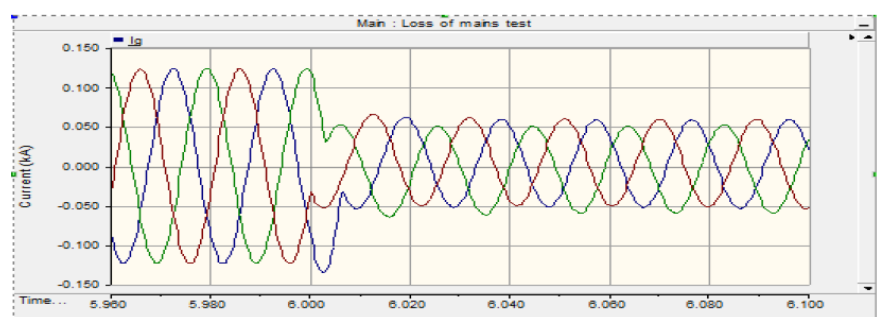

Fig. 9. Disconnection of mains.

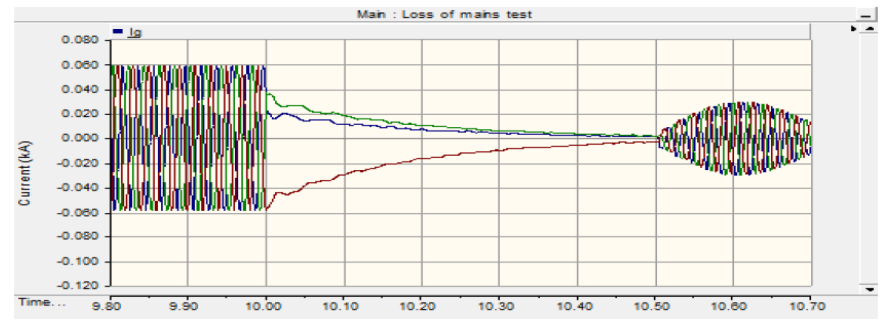

Fig. 10. Results of three-phase fault applied.

Normally if a fault were to be applied in the same location without the grid input being disconnected the circuit breaker would have been triggered, it would have opened and the fault would have been cleared. In this case though as the grid input has disconnected the operating current under normal conditions has dropped. As the normal operation current has dropped the fault current has also dropped. In this test the fault current after the mains had been disconnected was not detected by the circuit breaker protection system in the circuit. This meant that the fault current caused at 10 seconds was not cleared from the system and was free to impact other parts of the system. This test showed the once the mains is disconnected a new protection scheme would be needed as none of the protection schemes used in the network were able to detect the fault current and clear it. In a real system this fault current could potentially impact and damage other parts of the system. The current protection schemes implemented in this grid system are inadequate for this fault condition which suggests a redesign would be required perhaps using different technology or fault detecting techniques. Due to the difference in magnitudes between the two different fault currents the protection system could either be set to deal with the grid connected fault currents or the loss of mains fault currents not both. If the protection systems were set up to deal with the loss of mains fault currents then they would constantly be tripping during normal operation connected to the grid.

A potential solution to this problem could be smart relays or relay to relay communication [14]. These are relays that are able to communicate with other relays and ideally the rest of the grid system. If a signal were to be sent to the rest of the protection systems on the network when the mains is lost. Assuming they have the functionality the relays, could set themselves to different parameters. Ideally if the mains of a grid system were to be disconnected there should be a way of notifying the relay so its protection settings can change and adjust for the loss of mains fault levels. This would mean that the relay would essentially have two different fault levels. One for the grid connected system which typically has higher fault currents and then one for the system without a grid connection that typically has lower fault currents. This would make for a much more versatile and adaptive protection system as it would be able to have a number of settings that would be able to handle a number of different scenarios.

Another solution could be to use rate of change of frequency protection (ROCOF). This is a protection system that monitors the change of the frequency of the system. For loss of mains this form of protection would work as the mains connection is used to synchronise the rest of the systems. When the mains is disconnected the frequency of the system drifts from what it was. The ROCOF protection would detect this change in frequency and would then trigger, this would limit the impact that the loss of mains situation would have on a system.

\section{F. Blinding of Protection}

This is to test how the connection of distributed generators could affect the fault current experienced by the load. All of the distributed generators were disconnected leaving just the grid input connected. A three-phase to-ground fault was then applied to the bus bar the load was connected to. Different generators were connected and disconnected to see what impact different distances had with regards to altering fault current levels. The results in the below show the data collected for the blinding of protection test. The results are expected to show that when a distributed generator is connected to the grid it has an impact of the fault current seen by the network.

Fig. 11 shows the results for the blinding of protection test. For this test a three-phase fault was applied at a given time and lasted for 0.5 seconds. The fault was applied at 7 seconds to the busbar that was connected to the load. The initial results had to be processed, when acquiring the results the current for each phase is recorded at time increments of 50 micro-seconds $(\mu \mathrm{s})$. In order to get readable results from this test each period of the waveform was sampled to find the peak value for that period. This value is what is plotted on the graph and represents the peak value for the fault current experienced. Due to the high resolution of the data capture used in the software some data processing techniques were needed to sample the peak parts of the fault current. 


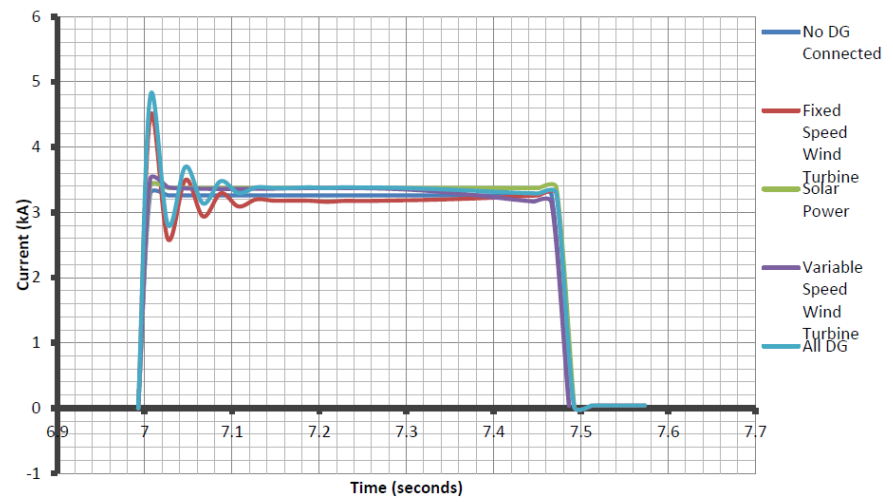

Fig. 11. Simulation results of the blinding of protection.

The results show that the topology of the network does affect how much of an impact the distributed generators can have when connected to the network. The generator closest to the load, the fixed speed wind turbine seems to have the biggest effect on the fault level seen by the load when it is connected. As the rest of the generators are further away from the fault location they have less of an impact on the fault level. This can be seen in Fig. 11 where the connection of the fixed speed wind turbine noticeably affects the fault current level, when this is disconnected and another generator is connected the difference is not as great. This difference as previously stated is due to the difference in distance between the generation points and the fault location. In order to suggest an optimal solution further research would need to be done to fully evaluate the extent of this problem. One solution to the problem although not ideal would be a complete overhaul of the systems protection systems when a new form of generation is added to the system. This is not ideal as it would require a lot of man hours and could be difficult to implement. This solution would however solve the problem as the new generator would no longer be added on to the existing protection system but would have its own protection system.

The topology of each different system needs to be assessed individually with regards to the blinding of protection. As each different topology of a system will have different impacts on the fault currents seen by the load. This means there is no quick fix to this problem as each different system is unique. A solution as previously would be to reconsider the design of the network protection trip levels when a new distributed generator is connected to a system. This problem would require further investigation to provide a more firm solution. Currently however with the data gained from this experiment it can be seen that each different topology has its own impact on the fault current seen by the load on the system.

\section{CONCLUSION}

This paper presents review and discussions with simulation results on potential impacts of distributed generation can have on LVDN protection systems. A suitable and effective solution for each of the situations tested for in this study needs to be developed. This will require further study to develop a much smarter and adaptive protection system as there is no one blanket solution to each of the problems. This report has provided speculation on potential solutions but further investigation would be required to effectively implement and test these solutions to evaluate their merits. It should also be noted that, for LVDN, distribution management system (DMS) is in its infancy and expensive since current LVDN do not have enough instrumentation for full observation of the system. To avoid the reliance on communication systems, research need to be done based on limited number of intelligent electronic devices (IEDs), based on advanced communication infrastructure. It is also essential to ensure that settings chosen for protection relays take into account the flexibility of grid topology and changes in location, type and amount of generation; otherwise the purpose of microgrid operation is compromised.

\section{REFERENCES}

[1] R. Ayyanar, G. T. Heydt, N. Nimpitiwan and S. Suryanarayanan, "Fault Current Contribution From Synchronous Machine and Inverter Based Distributed Generators," IEEE Transactions on Power Delivery, vol. 22, no. 1, pp. 634-641, 2007.

[2] S. Chaitusaney and A. Yokoyama, "Impact of Protection Coordination on Sizes of Several Distributed Generation Sources," in the 7th International Power Engineering Conference, Singapore, 2005.

[3] M. E. Baran and I. El-Markaby, "Fault Analysis on Distribution Feeders with Distributed Generators," IEEE Transactions on Power Systems, vol. 20, no. 4, pp. 1757-1764, 2005.

[4] K. Kauhaniemi and L. Kumpulainen, "Impact of Distributed Generation on the Protection of Distributed Networks," in 8th IET International Conference on Developments In Power System Protection (DPSP), 2004.

[5] S. de Haan and J. Morren, "Impact of Distributed Generation Units With Power Electronic Converters on Distribution Network Protection," in 9th IET International Conference on Developments in Power System Protection (DPSP), Glasgow, UK, 2008.

[6] A. Abusara, B. Hussain, S. Hussian and S. Sharkh, "Integration of Distributed Generation into the Grid: Protection Challenges and Solutions," in 10th IET International Conference on Developments In Power System Protection (DPSP), Manchester, UK, 2010.

[7] P. Jarventausta, A. Kulmala, K. Maki and S. Repo, "Studies on Grid Impacts of Distributed Generation in Combined Real-Time Simulation Environment," in International Conference on Power Systems Transients, Lyon, France, 2007.

[8] T. S. Sidhu, A. Yazdani and M. Zamani, "Investigations Into the Control and Protection of an Existing Distribution Network to Operate as a Microgrid: A Case Study," IEEE Transactions on Industrial Electronics, vol. 61, no. 4, pp. 1904-1915, 2014.

[9] K. Kauhaniemi, L. Kumpulainen and I. Ristolainen, "Loss-Of-Mains Protection- Still an issue with distributed generation," in 19th Internation Conference on Electricity Distribution, Vienna, 2007.

[10] E. El-Saadany, M. Salama and H. Zeineldin, "Distributed Generation Micro-Grid Operation: Control and Protection," in Power Systems Conference: Advanced Metering Protection, Control, Communication and Distributed Resources, Clemson, SC, 2006.

[11] T. C. Green and M. Brucoli, "Fault Behaviour in Islanded Microgrids," in 19th International Conference on Electricity Distribution, Vienna, 2007.

[12] R. Dugan and T. McDermott, "Operating Conflicts for Distributed Generation on Distribution Systems," in IEEE Rural Electric Power Conference, Knoxville, TN, 2001.

[13] G. Anotonova, M. Nardi, M. Pesin and A. Scott, "Distributed Generation and Its Impact on Power Grids and Microgrids Protection," The National Institue of Standards and Technology.

[14] K. Behrendt, "Relay-to-Relay digitial logic communication for line protection, monitoring and control," Schweitzer Engineering Laboratories Inc, Pullman, Washington USA, 1998. 